\title{
Investigation of the Fertilizer Fire aboard the Ostedijk
}

\author{
RORY HADDEN, FREDDY X. JERVIS and GUILLERMO REIN \\ BRE Centre for Fire Safety Engineering \\ The University of Edinburgh \\ King's Buildings \\ Edinburgh, EH9 3JL \\ UK
}

\begin{abstract}
This paper provides an account of a self-sustaining decomposition event of the NPK (Nitrogen, Phosphorous and Potassium) fertilizer freight aboard the ship Ostedijk. The fire developed inside the cargo hold for several days until it was controlled. Analysis of plume images shows a rapidly growing fire and provides an estimate of the evolution of the mass loss rate, ranging from approximately $0.5 \mathrm{~kg} \cdot \mathrm{s}^{-1}$ the first day to $12 \mathrm{~kg} \cdot \mathrm{s}^{-1}$ on the last day. Small-scale experiments were conducted to gain an insight into this incident. A three step decomposition mechanism is observed leading to a self-sustained reaction reaching $250-275^{\circ} \mathrm{C}$. The measured heat of reaction is $6.1 \mathrm{MJ} / \mathrm{kg}$, about one third of the value for flaming wood. Measurements are applied to the Ostedijk events and allow estimation of the maximum fire size to be in the order of $70 \mathrm{MW}$. Incidents of this nature challenge the traditional concept of fire, since self-sustaining decomposition events are thermal runaways involving exothermic reactions but not based on oxygen chemistry. However, application of fire engineering concepts and experiments allows the study of the processes.
\end{abstract}

KEYWORDS: ammonium nitrate, NPK, self-sustained decomposition

\section{INTRODUCTION}

In February 2007, the fertilizer aboard the cargo ship Ostedijk underwent a chemical reaction for seven days, destroying part of the cargo and compromising the ship. The incident took place off the coast of Galicia in Northeast Spain and generated a large plume of irritant gases easily seen from the coast.

The incident was closely followed in the Spanish media [1-19]. The main observation from the photographic evidence and witness accounts was that of plume growth throughout the event. During the first days, the plume appeared small, about $0.5 \mathrm{~m}$ diameter, was rapidly dispersed by the wind and white in colour. As the incident continued, the plume became denser and took on an orange colour. Five days into the event, the plume fully developed into a dense white cloud about $20 \mathrm{~m}$ in diameter. Thermal cameras were deployed by emergency personnel and measured surface temperatures of the fertilizer cargo in excess of $175^{\circ} \mathrm{C}$ [15] indicating that the inside of the cargo was at significantly higher temperature than this. Although the composition of the plume gas was not measured, it is likely that it contained the typical products of fertilizer decomposition i.e. nitrogen, nitrogen oxides, nitrous oxide, water vapour, ammonium chloride, hydrochloric acid and chlorine [20, 21].

Initial fire fighting aboard the Ostedijk consisted of cooling the outside of the hold with water from a nearby auxiliary ship. This started on the fourth day but proved ineffective in controlling the fire [2]. On day 5, specialist salvors opened the hold and identified several hot spots [15]. The hotspots were then targeted with localised water injection. It was necessary to use localised application of water as flooding of the cargo hold would have endangered the stability of the ship. On the seventh day, the fire was declared extinguished.

The official standing of the Spanish authorities is that the incident was a self-sustained 'fermentation' reaction, referring to a self-sustained decomposition (SSD) event. SSD is the phenomenon in which a locally initiated decomposition will spread throughout the mass of reacting material. The SSD nature of this accident is confirmed here by comparison of the evidence to observations during other SSD events described in the literature [20,22] and by the small-scale experiments conducted in this study. 


\section{The Ostedijk}

The Ostedijk was a general cargo ship built in 2006 in China and operated by a Dutch shipping company with flag from Antigua and Barbuda [23]. The vessel is a Bulk Carrier of approximately 7600 dead weight tonnes (dwt), $120 \mathrm{~m}$ in length and $16.8 \mathrm{~m}$ in width and a cruising speed of 11 knots $(5.6 \mathrm{~m} / \mathrm{s})$. The incident occurred while the Ostedijk was transporting a $6012 \mathrm{t}$ cargo of NPK fertilizer from Porsgruun, Norway to Valencia, Spain. Cargo hold 1 contained $3385 \mathrm{t}$ and cargo hold 2 contained $2627 \mathrm{t}$. She was manned by a crew of 12 .

The cargo was inorganic, mineral fertilizer NPK 15.15.15 manufactured in Norway [21]. The historical naming convention of fertilizer means it can be deduced that this material contains $15 \%$ nitrogen $(\mathrm{N})$ as ammonium and nitrate salts, $15 \%$ phosphorous (P) pentoxide as phosphates and $15 \%$ potassium (K) oxide as potassium chloride and potassium oxide. The remaining portion of the fertilizer consists of micronutrients (magnesium, sulphur, calcium etc) and anticaking agents. The material is of a granular nature with a bulk density in the range $0.9-1.2 \mathrm{~g} \cdot \mathrm{cm}^{-3}$ and particle diameter in the range 2-4 $\mathrm{mm}$. Fertilizers are used to promote crop growth by enhancing nutrient concentration of the soil.

Material of this nature is known to undergo self-sustaining decomposition (SSD) [25] reactions upon exposure to a heat source due to a significant fraction of the material being ammonium nitrate (AN). The nature of AN is such that it can undergo exothermic decomposition at temperatures between 200-230 C [26]. AN is a strong oxidising agent, which if in contact with burning organic materials (such as gasoline and cellulose based products) it will significantly increase the combustion rate. At elevated temperatures and when mixed with organic materials, the presence of AN may cause the mixture to detonate.

\section{INCIDENT TIMELINE}

Information on the incident was gathered from the Spanish national press [1-19] and an investigation report by the manufacturer [21]. Although these provided only limited information, the photographic evidence and witness accounts allowed the development of a timeline showing key events that occurred during the incident.

At 0150 on the $17^{\text {th }}$ February, the Captain of the Ostedijk made the first emergency call and stopped the engines while the vessel was approximately $50 \mathrm{mi}$ North West of A Coruna. He reported a "chemical reaction" and fumes escaping cargo hold 2. The Spanish authorities sent a support team and a tugboat pulled the vessel to a sheltered position $14 \mathrm{mi}$ off A Coruna. An inspection did not find any anomalies and at 2251 the vessel was allowed to continue accompanied by a tugboat. Photographic evidence shows wispy white smoke emitted from vents in the cargo hold rapidly dispersed by the wind.

The next day, at 1210 while approximately 34 mi North of Cabo Vilan, the captain radioed again informing of the continuation of the chemical reaction in cargo hold 2. The vessel was towed to more sheltered waters $14 \mathrm{mi}$ North of Ria de Vivieiro but was not allowed to enter port. Spanish authorities began consultation with technical experts. Meanwhile, all crew were evacuated and four members were airlifted to hospital having been affected by the fumes. Figure 1 shows gas being emitted from cargo hold 2 on $18^{\text {th }}$ February, the second day.

By the third day, the plume had grown larger in volume and density and took on an orange colour. It was still easily dispersed by the wind with the visible plume extending only a few meters from the deck. The rough seas hampered the work of the emergency services.

The fire fighting efforts began on the $20^{\text {th }}$ February, the fourth day, when a tugboat sprayed the outside of hold 2 with a water canon. This had little or no effect and the reaction, deep inside the hold, continued as evidenced by the increasing size and density of the plume.

On the fifth day, the plume increased in size to many times the ships length when emergency personnel sent aboard opened the cargo hold. A salvage company was then appointed on the $22^{\text {nd }}$ February to provide specialized assistance and took control of the incident from the Spanish emergency services. They identified the hot spots in the cargo and inserted injection pipes to deliver water to these zones. Over the next couple of days, the fire is brought under control until it was declared extinguished on $23^{\text {rd }}$ February (day 7). About $240 \mathrm{~m}^{3}$ of water had been delivered with the spear pipes. The estimated maximum water accumulation in the cargo before the ship stability would be compromised was $500 \mathrm{~m}^{3}$ [21]. 


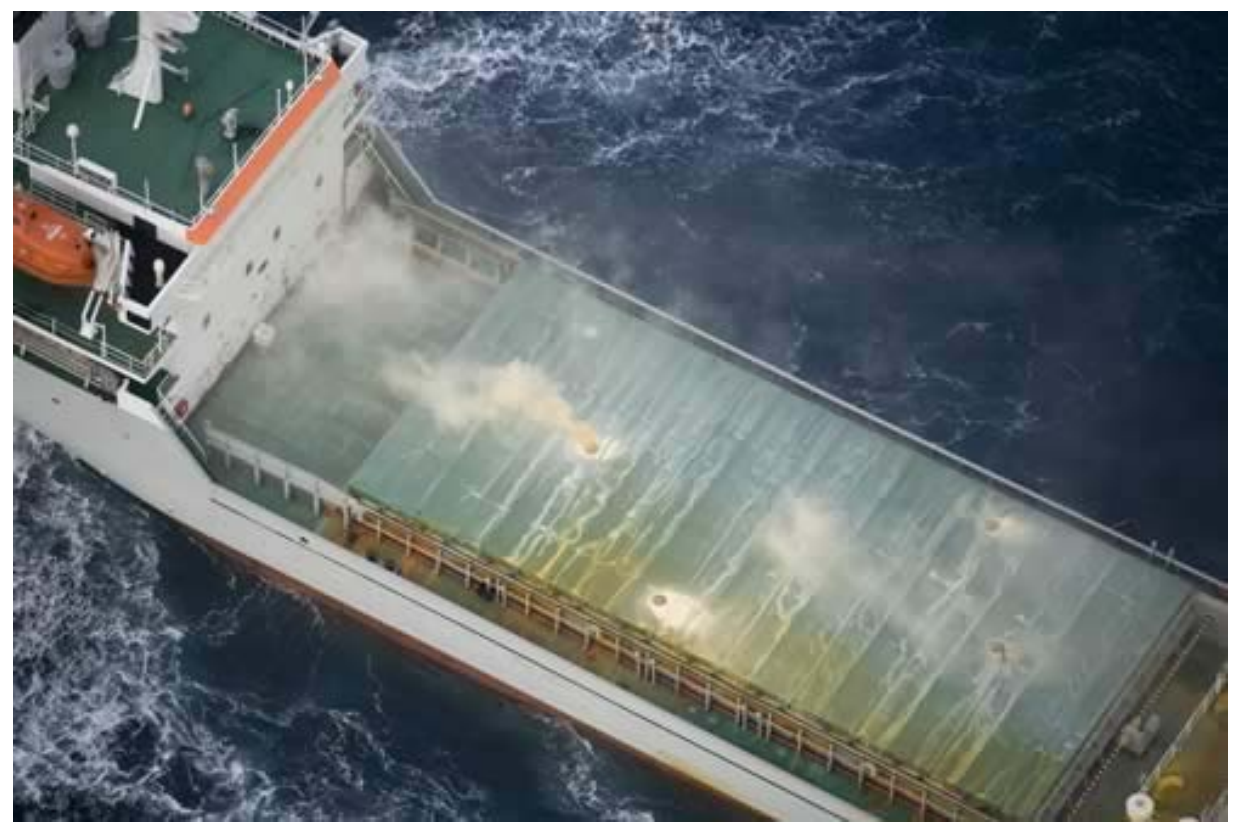

Fig. 1. The Ostedijk on the $18^{\text {th }}$ February (day 2) where the initial gas plume from the cargo can be seen. Photograph from La Voz de Galicia [6]

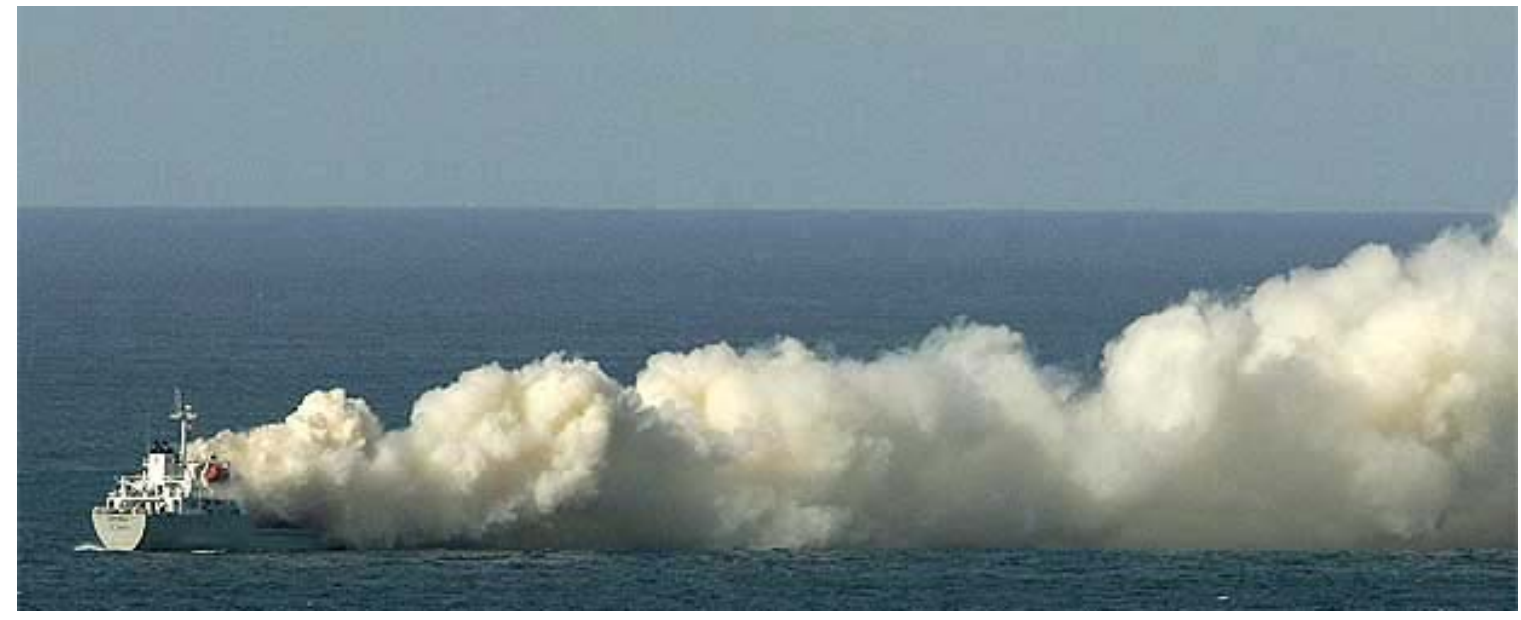

Fig. 2. The Ostedijk on $21^{\text {st }}$ February (day 5) after the hold was opened and before specialized fire fighting activities had commenced. Photograph from Agencia EFE [27].

On the $28^{\text {th }}$ February, the vessel is deemed seaworthy and allowed to sail to the nearby port of Bilbao. A team from the salvors remained on board and the vessel was escorted by a fire fighting tug. The following day (day 13, $1^{\text {st }}$ March) the vessel arrived in Bilbao. Photographic evidence sourced prior to unloading of the cargo suggests that approximately one third of the cargo was consumed during the event [28]. By the $6^{\text {th }}$ March, the cargo had been unloaded and the vessel was delivered to her owners. 


\section{PLUME ANALYSIS}

Using the photographic evidence, weather reports and material properties it is possible to estimate the plume flowrate from the cargo hold over the course of the incident. Calculation of the flow rate provides a quantification of the size and evolution of the event. These calculations aim only to give an order of magnitude indication of the flow and a general indication of the growth of the event. Estimation of the flow rate can be correlated with measurements from laboratory experiments as demonstrated in later sections.

From day 1 to day 4, the plume flowrate was calculated via velocity resolution using the wind speed and the angle of deflection of the gases escaping the hold as seen in the available images. When possible, different images of the same day were used in order to give a range of flow rates. From weather reports [3] the wind speed was estimated to be in the range 10 to $12 \mathrm{~m} \cdot \mathrm{s}^{-1}$. The angle of plume deflection varies from $10^{\circ}$ from the horizontal on the first day to $40^{\circ}$ on the fourth day. Assuming the wind velocity provides the horizontal component of the gas flow, the vertical component can be calculated. Multiplication of the resulting vertical velocity and the area of the hold vents gave the volumetric flowrate of gas escaping the hold. The density of the plume was calculated at the decomposition temperature $\left(200^{\circ} \mathrm{C}\right)$ and found to be $0.89 \mathrm{~kg} \cdot \mathrm{m}^{-3}$ which allowed the volumetric flowrate to be converted to a mass loss rate. Upon opening of the hold on day 5, and the formation of a large, continuous plume, Gaussian plume theory [15] was used instead of velocity resolution. The flow rates are presented in fig. 3.

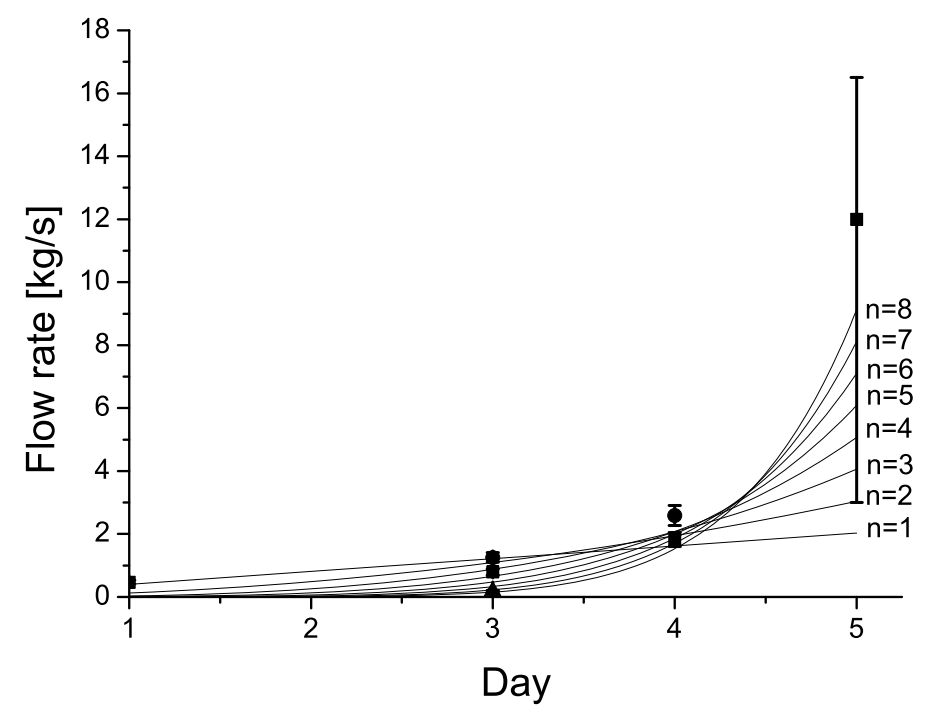

Fig. 3. Estimation of plume mass flowrate from cargo hold 2 on the Ostedijk during the course of the incident. All power law growth rates shown comply with the observed total mass loss of fertilizer.

If it is assumed that the flow rate follows a power law of the form,

$$
\text { (Mass loss) }=A \times(\text { time })^{n}
$$

then, the plume evolution is described by two parameters, the exponent $n$ and the factor $A$. The higher the value of $n$, the greater propensity the reaction has to self accelerate. The constraint on the power laws here is from the photographic evidence which suggests approximately one third of the cargo in hold 2 was involved in the event. From the small scale experiments described later, it is known that only $49 \%$ of this value will be lost in the plume. This mass loss gives us a constraint to which the power law must abide i.e. upon integration with respect to time, the value can not exceed that mass lost from the cargo hold. Given the uncertainty ranges in the estimations using photographic evidence, many different power laws can explain the plume growth. Figure 3 shows the power laws which give the calculated mass loss and fall within the error of the evidence. 


\section{SELF-SUSTAINING DECOMPOSITION EVENTS}

Self-sustaining decomposition (SSD) is the phenomenon in which a locally initiated decomposition will spread throughout the mass of material. Reactions of this nature generally consist of two steps: an endothermic "pyrolysis" and the exothermic decomposition. If the process is globally exothermic then selfsustained propagation of the decomposition front through the material is possible. Elevating the mass of material to the decomposition temperature and overcoming the endothermic step requires heat from an external source or the exothermic decomposition of surrounding material. In the case of ammonium nitrate (AN) containing fertilizer, the exothermic decomposition is that of AN to gaseous products [29]. The following chemical components are required [25]: nitrate ions $\left(\mathrm{NO}_{3}{ }^{-}\right)$, ammonium ions $\left(\mathrm{NH}_{4}{ }^{+}\right)$and chlorine ions $\left(\mathrm{Cl}^{-}\right)$. Typically, a matrix of condensed matter is formed behind the decomposition front which enhances propagation by reducing heat losses to the surroundings [6]. If a material has a strong propensity to melt before reaching the decomposition temperature, self-propagation is less likely [22].

An analogy can be drawn to smouldering combustion [30]. In smouldering, the pyrolysis of the material is the endothermic step followed by the exothermic thermal oxidation. Both of these reactions occur in porous media with the necessity for heat transfer to allow propagation of the reaction front. The primary difference is that smouldering consumes oxygen and is limited by the rate of oxygen transport whereas SSD does not consume oxygen and is largely independent of gas phase mass transfer.

Ammonium nitrate containing fertilizers are classed according to their reactivity [31]. Class A are the most reactive and have a composition of more than $90 \%$ ammonium nitrate. These are oxidizing agents; they will assist combustion of carbon-based materials and in a major fire can give rise to explosions. Class B fertilizers are associated mainly with the hazard of SSD but are not oxidizing agents and pose a low risk of explosion. Class C fertilizers, such as the 15.15.15 NPK blend aboard the Ostedijk, are considered to be non hazardous.

SSD is a hazard of particular importance during the manufacture, transport and storage of fertilizers [32]. There are many reported industrial incidents involving AN containing fertilizers - most of these took place when fertilizer had come into contact with organic material and assisted the burning of the organic material often resulting in an explosion. Perhaps the most well known incident involving AN is the explosion in Texas City in 1947 (the interested reader is directed to [33]). This remains the largest industrial accident in America with 581 deaths and more than 5000 injuries. However, since then there have been significant advances in the manufacture of fertilizers and more stable varieties are now the norm. A review of these events can be found in [32].

SSD incidents can be initiated by self-heating or by external heat sources. Self-heating is promoted when large quantities of fertilizer remain undisturbed for long times e.g. in bulk storage or transportation which allows heat to accumulate in the mass of material [34]. This is especially prevalent at elevated ambient temperatures or if there has been contamination of organic substances [25]. Examples of dangerous external heat sources are hot work, hot surfaces and embers in contact with the material. For the most reactive fertilizers, even a spark may be capable of ignition. SSD events are rare with one occurring worldwide on average every 3 years [22]. The consequences can be severe with direct casualties and toxic plumes. Incidents involving SSD of AN-based fertilizers include a warehouse in Cartagena, Spain in 2002, on Humber coast in North East England in 1993 and Nantes, France in 1987 [20, 32]. These incidents resulted in formation of a large, toxic plume and were initiated by relatively small heat sources e.g. electric lamps or faults in electric equipment. Kiiski [22] gives a review of SSD incidents dating back to the early 1960s.

\section{Decomposition mechanisms of AN-based fertilizers}

The decomposition chemistry of these fertilizers is complex. The nature of AN-based fertilizers is such that endothermic decomposition and melting starts at around $190^{\circ} \mathrm{C}$ and exothermic decomposition starts between $200-230^{\circ} \mathrm{C}$ [26]. There are two decomposition mechanisms which are presented in detail by Kiiskii [22]: non-catalysed and catalysed decomposition. The catalysed decomposition requires the presence of chlorine ions which are not consumed directly by the decomposition. SSD will only take place if sufficient heat is liberated to drive the endothermic steps. The steps in the catalysed decomposition are: 1) formation of nitric and hydrochloric acids; 2) chain reaction with ionic and radical steps; 3) conversion of potassium nitrate to potassium chloride. The temperature during decomposition must be above $300^{\circ} \mathrm{C}$ to 
convert the potassium nitrate in step 3. For the non-catalysed decomposition, the reaction steps are: 1) ammonium nitrate dissociates to ammonia and nitric acid, 2) decomposition of nitric acid.

Little information is available on the precise decomposition chemistry of AN-based fertilizers as the compositions can vary greatly. However, in industrial fertilizers, the catalysed reaction is most common as fertilizers contain chlorine in the form of potassium chloride [25]. Equation (2 details the unbalanced chloride catalysed reaction.

$$
\mathrm{NH}_{4} \mathrm{NO}_{3} \stackrel{\mathrm{Cl}^{-}}{\rightarrow} \mathrm{NH}_{3}+\mathrm{HNO}_{3} \rightarrow \mathrm{N}_{2}+\mathrm{H}_{2} \mathrm{O}+\mathrm{HNO}_{3}+\mathrm{NO}_{x}
$$

\section{LABORATORY EXPERIMENTS}

Small-scale experiments of reactivity were carried out to investigate the decomposition behaviour and controlling mechanisms of the NPK fertilizer. Experiments were carried out substituting NPK 15.15.15, which is not available in the UK, with a 16.16 .16 blend which is similar in nature i.e. thermal properties, particle size and composition. Since this paper aims to give an overview of decomposition mechanisms and not a detailed study, these materials are sufficiently close in properties and composition to draw useful conclusions. The experimental findings are applied to the case of the Ostedijk in the last section.

\section{Propagation experiments}

The decomposition behaviour and subsequent classification of AN containing fertilizers is determined by a standardized propagation test (the "Trough Test") as detailed in UN Recommendations on the Transport of Dangerous Goods [34]. The apparatus consists of a gauze trough of dimensions $150 \times 150 \times 500 \mathrm{~mm}$ filled with the fertilizer to be tested. The trough is heated at one end with a hot plate and lateral propagation of the decomposition front though the material is measured by recording the time at which a temperature rise is recorded by thermocouples placed throughout the sample. This test provides only limited information i.e. whether or not the fertilizer will support SSD under the prescribed conditions and therefore it is not always applicable to other situations where the conditions are different.

The propagation experiments performed here are similar to the Trough Test but using a box constructed from insulation board. The dimensions of the box were $100 \times 100 \times 50 \mathrm{~mm}$ with a lid of aluminium foil. Thermocouples were placed throughout the sample to monitor ignition and propagation. Coiled Nichrome wire was used as the heat source for ignition. This set-up provides an insight into the ignition of SSD and the conditions necessary for propagation of the decomposition front. The results show two distinctive reaction steps. Initially, the temperature increases at a uniform rate until the fertilizer melts at around $120^{\circ} \mathrm{C}$. During this stage, the plume is weak and white in colour. The second step involves a sharp increase in the temperature to between $250-275^{\circ} \mathrm{C}$. The gases at the onset of this reaction are of an orange/yellow hue and, as the reaction continues, a denser white plume forms.

From these experiments, it can be concluded that ignition of the SSD occurs at temperatures above $120^{\circ} \mathrm{C}$ and is characterized by an orange plume. Sustained propagation reaches temperatures between $250-275^{\circ} \mathrm{C}$ and emits a white plume.

The samples showed significant mass loss in the reaction zone as well as a colour gradient from white (completely reacted material), through grey (partially reacted, pyrolized material), to pink (melted, agglomerated granules).

The reaction as observed in the propagation experiments suggests complex kinetics. In order to gain a better understanding, further experiments on the fundamentals of SSD reactivity paths were carried out.

\section{Reactivity experiments}

The Fire Propagation Apparatus (FPA) [36] was used to investigate the decomposition behaviour and determine the mass loss, gas emissions and heat released rate (HRR) during the reaction. Small samples of about $130 \mathrm{~g}$ of fertilizer were placed in a container of diameter $100 \mathrm{~mm}$ forming a layer $25 \mathrm{~mm}$ deep. The samples were exposed to an external heat flux of $20 \mathrm{~kW} \cdot \mathrm{m}^{-2}$ for different times. All samples underwent decomposition and some reached self-sustained decomposition depending on the exposure time. 
The FPA, though designed for use with traditional oxygen-based chemistry fires, allows measurement of mass loss and heat release rate. Fig. 4 shows the mass loss in a sample exposed to the heat flux for $700 \mathrm{~s}$. Three distinct regimes of mass loss are apparent: 1$)$ slow mass loss rate during heating phase (0-600 s); 2) moderate mass loss rate (600-850 s); and 3) severe mass loss rate (850-1100 s). Burn out of the sample mass was reached after $1100 \mathrm{~s}$. The rates of mass loss in the different regimes are 81,408 and $590 \mathrm{~g} \cdot \mathrm{s}^{-1} \cdot \mathrm{m}^{-3}$ respectively. The mass loss rate is expressed per unit volume of the reaction front, assuming that SSD scales with the sample volume. This assumption holds well during the two last regimes which are observed to involve most of the sample volume.

The mass loss measurements indicate that a fraction of the fertilizer is not released as gas during decomposition but remains in the holder as a condensed phase. This remaining material accounts for approximately $51 \%$ of the initial mass and, once cooled, has a porous structure white in colour and mostly inert (i.e. of mineral origin).

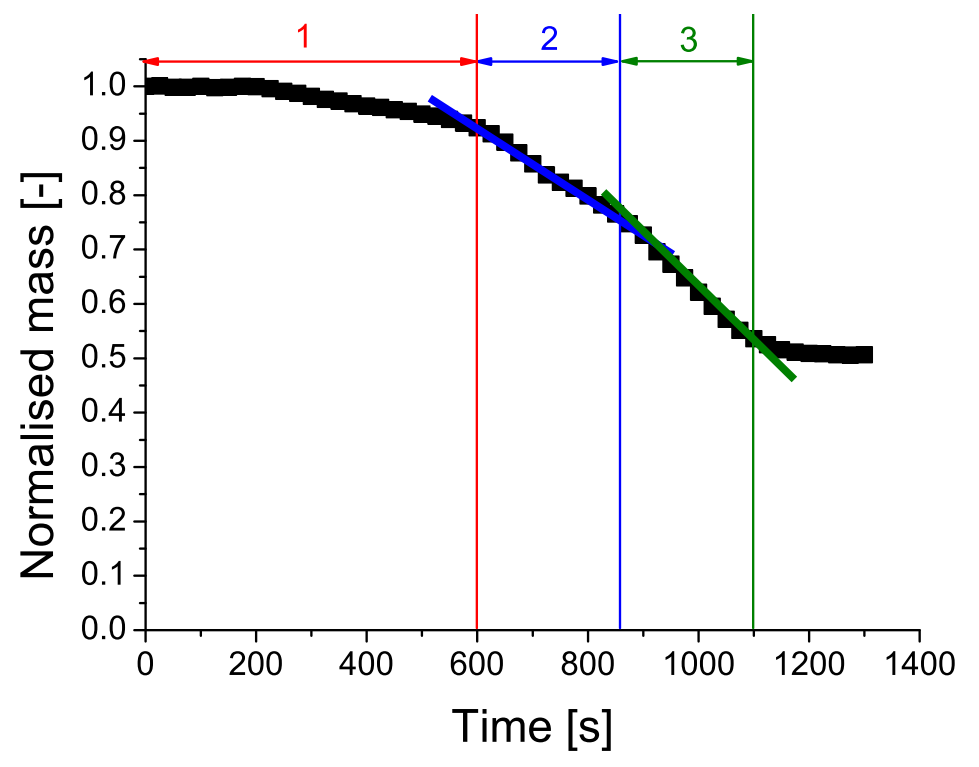

Fig. 4. Mass loss of the NPK sample for an external heat flux of $20 \mathrm{kWm}^{-2}$ and switched off at $700 \mathrm{~s}$.

The FPA allows measurement of $\mathrm{O}_{2}, \mathrm{CO}$ and $\mathrm{CO}_{2}$ concentrations in the reaction gases and the convective heat release rate [35]. Analysis of the product gases shows that oxygen concentration stays at ambient levels during the experiment indicating that the SSD neither consumes nor releases oxygen. Likewise, carbon dioxide and carbon monoxide concentration remain at ambient levels and thus are not produced. Figure 5 shows the HRR growth-peak-decay curve resulting from the same experiment as in Fig 4. During the growth phase, the reaction front propagates and increases in volume until, at the peak (approx $600 \mathrm{~s}$ ), the entire volume of the sample is reacting. As the reactive fraction of the sample is gradually consumed, the HRR decreases. The average HRR is $3.6 \mathrm{MW} \cdot \mathrm{m}^{-3}$ with a peak measured at $5.5 \pm 0.5 \mathrm{MW} \cdot \mathrm{m}^{-3}$. Dividing the HRR by the mass loss rate, the calculated heat of reaction is $6.1 \mathrm{MJ} / \mathrm{kg}$, about one third of the value for flaming wood [37].

Upon observation of the distinct mass-loss regimes, further tests were carried out to determine the minimum exposure time for self-sustained ignition. The external heat flux was turned off at different times, 500, 600, 650, 675, 700 and $750 \mathrm{~s}$, and the reaction was allowed to continue until the mass loss rate was negligible. For exposure time below $700 \mathrm{~s}$, the reaction was not self-sustaining and the mass loss leveled off rapidly after shutting off the heat flux. In cases where the exposure time was higher than $700 \mathrm{~s}$, SSD was achieved. These results indicate that the three reaction regimes involve endothermic and exothermic reactions but that the first regime does not support SSD because it is globally endothermic (heat losses and endothermic reactions dominate). The second regime is the transition to self-sustaining reaction, and the third regime is globally exothermic and when self-sustained decomposition is achieved. 
Analysis of the samples after the reaction showed significant mass loss in the reaction zones as well as radial colour gradients. The core of the sample is white and has completely reacted leaving only the mineral fraction. The top of the sample, exposed directly to the external heat flux and the ambient air, has a brownish film of partially reacted liquid that solidifies upon cooling. The bottom and edges of the sample which are in contact with the sample walls are made of partially reacted and partially melted granules of the original pink colour. These observations of composition and colour gradients are in agreement with the observations made during the previous propagation experiments.

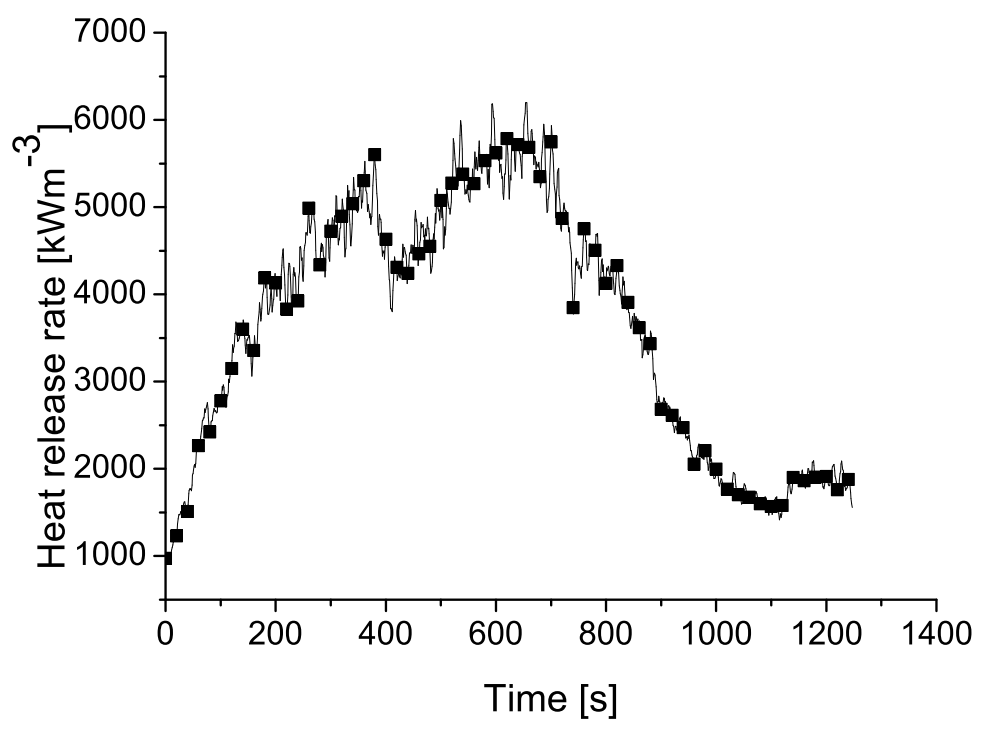

Fig. 5. Convective heat release rate from the NPK sample. The external heat flux was switched off at $700 \mathrm{~s}$

Based on the experimental observations and measurements both in the propagation box and the FPA, the proposed global mechanism and phenomenological description of the decomposition in a sample heated from the top is as follows: initial heating raises the temperature on the surface and heat is conducted into the sample. There is a small amount of fume-off from the surface as the fertilizer melts (eq. 5). The liquid fertilizer then begins to undergo significant fume off and as a result, the mass begins to decrease. This process is endothermic and requires heat to be supplied from an external source. Orange fumes are observed as the molten fertilizer is converted to an intermediate product, here referred to as $\beta$-melt (eq. 6). When the temperature reaches approximately $210^{\circ} \mathrm{C}$, the exothermic decomposition of AN starts and heat is released while white fumes are produced leaving the inert fraction is left as residue (eq. 7). The heat generated is partially transferred into the sample thus accelerating the decomposition reaction, and partially convected away with the gases.

$$
\begin{aligned}
& \text { Virgin fertiliser } \rightarrow \text { melt } \\
& \text { melt } \rightarrow \beta-\text { melt } \\
& \beta-\text { melt } \rightarrow \text { inert }
\end{aligned}
$$

These reactions occur throughout the sample but the overall propagation is from the free surface downwards into the body of the material. Figure 6 shows a schematic of the evolution after ignition of a SSD front through the depth of a sample as observed in the small-scale experiments. The reactions first occur on the top of the sample exposed to the external heat flux where the highest temperatures are reached. The reaction propagates through the sample as heat is transferred downwards and as a result, the reaction front increases in volume. During the growth phase of the reaction (before the peak HRR is reached), the upper part of the sample is undergoing exothermic decomposition while the bottom part is undergoing 
endothermic melting and pyrolysis and pre-heating. The peak HRR is reached when a maximum fraction of the sample volume is involved in the exothermic reaction (this is unlikely to be all of the material as some will have decomposed completely prior to this point). As the reaction consumes the fertilizer and the front size decreases, the HRR decays.

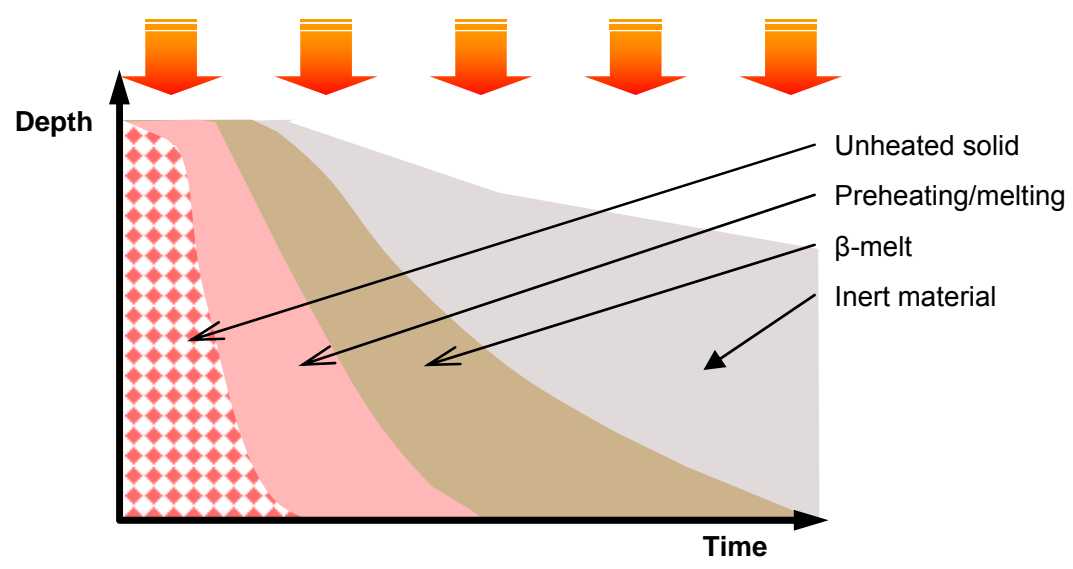

Fig. 6. Schematic of the in-depth evolution of a SSD front after ignition as gathered from observations in the small-scale experiments.

\section{APPLICATION TO THE OSTEDIJK}

Applying the results from the experimental investigations to the events aboard the Ostedijk allows us to draw some additional conclusions on the accident. The observed orange plume on the $3^{\text {rd }}$ day corresponds well to the ignition event in our experiments and would indicate that the fire is propagating to other locations of the cargo (suggesting perhaps a new hotspot developing). The white plume observed during most of the days would indicate sustained propagation with temperatures between $250-275^{\circ} \mathrm{C}$ in the bulk of the material.

Combining the plume analysis with the measured heat of reaction allows estimation of the HRR from cargo hold 2 of the Ostedijk. The flow of gases estimated in fig. 3 is the mass loss from the cargo hold due to the SSD. Thus, multiplication of the flow rate by the heat of reactions of $6.1 \mathrm{MJ} / \mathrm{kg}$ gives the HRR. By this calculation, it is estimated that the SSD was the order of magnitude of $3 \mathrm{MW}$ the first day and grow to a peak around $73 \mathrm{MW}$ on the fifth day. Moreover, the measured mass loss rates in the experiments can be applied to estimate the front size in the cargo hold. By dividing the gas flow rate from the cargo by the mass loss rate of SSD $\left(590 \mathrm{~g} \cdot \mathrm{s}^{-1} \cdot \mathrm{m}^{-3}\right)$, it is estimated that the reaction front grew from approximately $0.85 \mathrm{~m}^{3}$ the first day to $20.4 \mathrm{~m}^{3}$ on the fifth day.

Extrapolation of the plume gas flow (Fig 3) backwards in time gives an estimate of the time when ignition could have taken place. The upper and lower limits provide a range of between three and six days prior to the Captain's initial radio message on $17^{\text {th }}$ February when the fire could have started. At cruising speed of $11 \mathrm{knots}(5.6 \mathrm{~m} / \mathrm{s})$, the vessel will have travelled between 1400 and $2900 \mathrm{~km}$ in this time. The upper limit of six days indicates that the fire could have begun soon after the ship left the port of origin in Norway. More precise information on the event would allow for a better estimate of this time.

\section{FINAL REMARKS}

The analysis of the event has further indicated that the bulk cargo of NPK fertilizer aboard the Ostedijk underwent a self-sustaining decomposition reaction. The plume analysis shows rapid growth of the fire and allows estimation of the mass loss, HRR and the front size. Extrapolation backwards in time gives an indication that the fire started between the day of departure from Norway and three days before the initial alert. It is not within the scope of this paper to comment on the possible cause and origin or the ignition source. 
The small-scale experiments performed have given insight into the SSD behaviour of inorganic fertilizers. From the experiments, the temperature needed to reach a self-sustaining process is above $120^{\circ} \mathrm{C}$ and the steady-state range for SSD temperature in the bulk of the material is from 250 to $275^{\circ} \mathrm{C}$. The propagation process has been characterized and a phenomenological chemical mechanism is proposed based on the experimental observations.

Although NPK15.15.15 is classified as a class C fertilizer i.e. one which will not sustain decomposition in the trough test UN Transport Code, the fertilizer cargo ignited and an SSD fire grew rapidly for seven days. Our analysis of NPK 16.16.16 (also Class C) indicates that it can also sustain SSD under the right set of conditions. This points at the limitations of the trough test and the lack of attention given to fertilizer fires by the research community. Incidents of this nature which, due to the absence of oxygen chemistry, challenge the traditional concept of fire are sometimes studied by the chemical engineers but largely ignored by fire safety engineering. It is shown here that application of fire engineering concepts and experimental apparatus allows further study of the problem and expansion of the existing knowledge base.

\section{ACKNOWLEDGEMENTS}

Partial funding for this project was provided by International Fire Investigators and Consultants Ltd, Engineering and Physical Sciences Research Council (EPSRC) and the BRE Trust. Thanks to Robert Redpath at the Scottish Agriculture College for supplying the fertilizer for the experiments and to Jose Torero for his support and encouragement.

\section{REFERENCES}

[1] El «Ostedijk» se prepara para abandonar la costa de Lugo, La Voz de Galicia, 25 February 2007

[2] El «Ostedijk» retrasa su partida al no entregar el informe de navegabilidad, La Voz de Galicia, 27 February 2007

[3] Lo que no se supo del «Ostedijk», La Voz de Galicia, 27 February 2007

[4] El «Ostedijk» abandonó Galicia, La Voz de Galicia, 28 February 2007

[5] El buque 'Ostedijk' llegará esta tarde a una zona de refugio para enfriar su carga, El Mundo, 19 February 2007

[6] Riegan el 'Ostedijk' desde otro barco para tratar de enfriar su carga, El Mundo, 20 February 2007

[7] El Gobierno rechaza el plan del armador del 'Ostedijk' de descargar el fertilizante, El Mundo, 20 February 2007

[8] El Gobierno se hace cargo del buque 'Ostedijk' y lo lleva a una zona segura, El Mundo, 21 February 2007

[9] Salvamento Marítimo iniciará hoy el enfriamiento de la carga del 'Ostedijk', El Mundo, 22 February 2007

[10] Fomento anuncia que se ha logrado frenar la descomposición de la carga del 'Ostedijk', El Mundo, 26 February 2007

[11] Fomento anuncia que se ha logrado frenar la descomposición de la carga del 'Ostedijk', El Mundo, 26 February 2007

[12] El buque holandés 'Ostedijk' atraca en el puerto de Bilbao para descargar su mercancía El Mundo, 1 March 2007

[13] Comienza la descarga de fertilizantes del barco holandés 'Ostedijk' en el puerto de Bilbao, El Mundo, 3 March 2007

[14] E. Mouzo and P. González, "Un buque mercante que despedía gases tóxicos pone a prueba el dispositivo de salvamento gallego," La Voz de Galicia, 17 February 2007.

[15] "Fomento anuncia que se ha logrado frenar la descomposición de la carga del 'Ostedijk"' El Mundo, 26 February 2007. 
[16] Atendidos cuatro tripulantes del buque 'Ostedijk' por los gases emitidos al descomponerse su carga, El Pais, 18 February 2007

[17] El Gobierno pide al armador del 'Ostedijk' un plan de actuación urgente, El Pais, 19 February 2007

[18] El 'Ostedijk' tardará varios días en poder descargar el Fertilizante, El Pais, 2 March 2007

[19] Associated Press, "Spanish rescuers evacuate 4 crew from Dutch ship loaded with fertilizer," International Herald and Tribune, 18 February 2007

[20] A. M. Palomo, "Informe sobre el Accidente en Escombreras - Cartagena," Revista de Protección Civil 11, 2002.

[21] Yara International, "Decomposition of NPK 15-15-15 on m/v Ostedijk in February 2007 - Internal Investigation Report" 2007.

[22] H. Kiiski, "Self Sustaining Decomposition of Ammonium Nitrate Containing Fertilisers," presented at 70th International Fertiliser Association Conference, Paris, 2002.

[23] French Ministry for Transport, "Equasis" 2007.

[24] Yara International, "FICHA DE DATOS DE SEGURIDAD NPK 15.15.15," 2001.

[25] V. Babrauskas, Ignition Handbook, 1 ed: Fire Science Publishers, 2003.

[26] Kirk-Othmer Encyclopedia of Chemical Technology, editor J I Kroschwitz, vol. 10 John Wiley and Sons, 1994.

[27] Agencia EFE, 2007.

[28] Personal Communication, Subdirección General de Seguridad Marítima y Contaminación, Dirección General de la Marina Mercante, 2007

[29] S. R. Hanna and D. Strimaitis, Workbook of test cases for vapour cloud source dispersion models, American Institute of Chemical Engineers, 1989

[30] T. J. Ohlemiller, "Smouldering Combustion" SFPE Handbook of Fire Protection Engineering (3nd ed), DiNenno P.J. (ed.), National Fire Protection Association, Quincy, MA 02269, 2002, p. 2/200

[31] Handbook for the safe storage of ammonium nitrate containing fertilisers: International Fertilizer Industsry Association and the European Fertilizer Manufacturers Association, 1992.

[32] G. Marlair and M.-A. Kordek, Safety and security issues relating to low capacity storage of AN-based fertilisers, Journal of Hazardous Materials, vol. A123, pp. 13-28, 2005 http://dx.doi.org/10.1016/j.jhazmat.2005.03.028

[33] B. Minutaglio, City on Fire: The Explosion That Devastated a Texas Town and Ignited a Historic Legal Battle, 1 ed, HarperCollins, 2003

[34] D. A. Frank-Kamenetskii, Diffusion and Heat Transfer in Chemical Kinetics, 2ed., Plenum Press,1969, pp $374-421$

[35] UN, Recommendations on the transport of dangerous goods - Manual of tests and criteria, 2 ed: United Nations, 1995

[36] A. Tewarson, Generation of heat and chemical compounds in fires, 3 ed: Society of Fire Protection Engineers, 2002.

[37] D. Drysdale, An Introduction to Fire Dynamics, 2 ed, John Wiley and Sons, 1998. 
